\title{
EFFECT OF ALBUMIN DIALYSIS ON INTRACRANIAL PRESSURE INCREASE IN PIGS WITH ACUTE LIVER FAILURE: A RANDOMIZED STUDY
}

Sen, Sambit; Rose, Christopher; Ytrebø, Lars M.; Davies, Nathan A.; Nedredal, Geir I.; Drevland, Synnøve S.; Kjønnø, Marianne; Prinzen, Frits W; Hodges, Stephen J.; Deutz, Nicolaas E. P.; Williams, Roger; Butterworth, Roger F. ; Revhaug, Arthur; Jalan, Rajiv

S. Sen and C. Rose contributed equally to this work and are joint first authors.

From the Liver Failure Group, The UCL Institute of Hepatology, Division of Medicine, Royal Free and University College Medical School, London (SS, NAD, SJH, RW, RJ), London, UK; Department of Cellular Neuroscience, Max-Delbrück Center for Molecular Medicine (CR), Berlin, Germany; Department of Digestive Surgery, University Hospital Northern Norway (LMY, GIN, SSD, MK, AR), Tromsø, Norway; Department of Physiology, Cardiovascular Research Institute (FWP), and Department of Surgery (NEPD), Maastricht University, Maastricht, The Netherlands; and Neuroscience Research Unit, Hôpital Saint-Luc (RFB), Montreal, Quebec, Canada.

\section{ABSTRACT}

Background: Increased intracranial pressure (ICP) worsens the outcome of acute liver failure (ALF). This study investigates the underlying pathophysiological mechanisms and evaluates the therapeutic effect of albumin dialysis in ALF with use of the Molecular Adsorbents Recirculating System without hemofiltration/dialysis (modified, MMARS).

Methods: Pigs were randomized into three groups: sham, ALF, and ALF + M-MARS. ALF was induced by hepatic devascularization (time $=0$ ). M-MARS began at time $=2$ and ended with the experiment at time $=6$. ICP, arterial ammonia, brain water, cerebral blood flow (CBF), and plasma inflammatory markers were measured.

Results: ICP and arterial ammonia increased significantly over 6 hrs in the ALF group, in comparison with the sham group. M-MARS attenuated (did not normalize) the increased ICP in the ALF group, whereas arterial ammonia was unaltered by M-MARS. Brain water in the frontal cortex (grey matter) and in the subcortical white matter at $6 \mathrm{hrs}$ was significantly higher in the ALF group than in the sham group. M-MARS prevented a rise in water content, but only in white matter. CBF and inflammatory mediators remained unchanged in all groups.

Conclusion: The initial development of cerebral edema and increased ICP occurs independently of CBF changes in this noninflammatory model of ALF. Factor(s) other than or in addition to hyperammonemia are important, however, and may be more amenable to alteration by albumin dialysis.

Keywords: liver ischemia, cerebral blood flow, cerebral edema, inflammation

\section{INTRODUCTION}

Raised intracranial pressure (ICP), in conjunction with cerebral edema, is a common complication of acute liver failure (ALF), contributing significantly to mortality and morbidity (1-5). The underlying pathophysiological mechanisms are not entirely clear, but hyperammonemia is a consistent finding and is believed to play a major role 
Sen, S. et al., 2006. Effect of albumin dialysis on intracranial pressure increase in pigs with acute liver failure: a randomized study. Critical Care Medicine, 34(1), p.158-164.

(6). This is emphasized by studies in which ammonia-lowering strategies prevented brain edema and severe encephalopathy in rats with $\operatorname{ALF}(7,8)$. It has also been suggested that increased cerebral blood flow (CBF) may be coupled with intracranial hypertension in ALF (9). However, whether increased CBF is a cause of raised ICP (temporally preceding it), an effect, or just an association remains unclear. Recently, it has been demonstrated that other factors such as inflammation and subliminal infection may be involved in the pathophysiology of intracranial hypertension in ALF $(10,11)$.

Recent studies have investigated the role of Molecular Adsorbents Recirculating System (MARS) in liver failure (1214). This is an extracorporeal device (15-17) utilizing albumin dialysis with hemofiltration/dialysis to remove albumin-bound toxins (18) that accumulate in liver failure and thus may improve/prevent associated cerebral, renal, and circulatory disturbances $(12,19)$. One consistent observation with its use in patients with liver failure has been an improvement of hepatic encephalopathy $(12-14,20)$. However, most of the data pertain to patients with acute decompensation of chronic liver disease, and the effect of MARS therapy on cerebral status in ALF remains unclear.

A porcine model of ALF induced by hepatic devascularization has been developed and validated (21-24) and shows the characteristic rise of ICP, with a concomitant increase in blood ammonia and hyperdynamic vasodilated circulation, renal dysfunction, and worsening liver function characterized by coagulopathy and hyperbilirubinemia (21-24). The present study utilizes this model to better understand the pathophysiological basis of intracranial hypertension and investigates the impact of albumin dialysis with use of MARS without any hemofiltration/dialysis (which we have termed modified MARS [M-MARS]) on the development of increased ICP in ALF, in relation to arterial ammonia, cerebral edema (measuring brain water), $\mathrm{CBF}$, and plasma inflammatory mediators-factors thought to be of pathophysiological importance in ALF.

\section{METHODS}

The study was performed at the Surgical Research Laboratory, University of Tromsø, Norway, with approval of the Norwegian Experimental Animal Board. Twenty-four female Norwegian Landrace pigs from three different litters, weighing 23-30 kg (mean \pm sem, $26.8 \pm 0.3$ ) were used, and all the studies were performed by the same investigators (SS, CR, LMY, GIN, SSD, and MK) over a 3-month period. The operating theater and all the associated facilities remained unchanged throughout the experimental period.

\section{Study Design.}

The pigs were randomized according to sealed, prenumbered envelopes into one of three groups: sham, ALF, and ALF + M-MARS (eight per group) (Fig. 1). Details of the surgery, including sham operation, are described elsewhere $(21,24)$. In brief, in the sham group, sham abdominal surgery was performed without interfering with hepatic blood supply. In the other two groups, hepatic devascularization was performed by an end-to-side porta-caval anastomosis followed by hepatic artery ligation. Time $=0 \mathrm{hrs}$ was set with ligation of the hepatic artery (ALF, ALF + M-MARS) or completion of surgery just before the closing of the abdominal wall (sham). All pigs were monitored over the following $6 \mathrm{hrs}$. In the ALF + M-MARS group, albumin dialysis was instituted for $4 \mathrm{hrs,} \mathrm{from} \mathrm{time}=2-6 \mathrm{hrs}$. Experiments were terminated with an overdose of pentobarbital and potassium chloride at time $=6 \mathrm{hrs}$.

\section{The Animal Model.}

Details regarding animal room facilities, anesthesia, and surgical preparation has previously been reported (21-25). All animals received $500 \mathrm{~mL} 0.9 \% \mathrm{NaCl}$ containing $625 \mathrm{mg}$ of glucose as a preoperative load in order to prevent any preoperative dehydration. The pigs were premedicated with intramuscular ketamine $(20 \mathrm{mg} / \mathrm{kg})$ and atropine (1 $\mathrm{mg}$ ). Anesthesia was induced with an intravenous bolus of $10 \mathrm{mg} / \mathrm{kg}$ pentobarbital and $10 \mu \mathrm{g} / \mathrm{kg}$ fentanyl and was maintained during surgery with a central venous infusion of $4 \mathrm{mg} / \mathrm{kg} / \mathrm{hr}$ pentobarbital, $0.02 \mathrm{mg} / \mathrm{kg} / \mathrm{hr}$ fentanyl, and $0.3 \mathrm{mg} / \mathrm{kg} / \mathrm{hr}$ midazolam. Anesthesia was stopped after hepatic devascularization. If clinical signs of light sedation appeared, small doses of fentanyl and midazolam were given as boluses. Because of drug removal by MARS (25), ALF

The final publication is available at http://dx.doi.org/10.1097/01.CCM.0000196203.39832.3C 
Sen, S. et al., 2006. Effect of albumin dialysis on intracranial pressure increase in pigs with acute liver failure: a randomized study. Critical Care Medicine, 34(1), p.158-164.

+ MARS animals were kept sedated by a continuous infusion of $0.04 \mathrm{mg} / \mathrm{kg} / \mathrm{hr}$ fentanyl and $0.6 \mathrm{mg} / \mathrm{kg} / \mathrm{hr}$ midazolam, with additional boluses given when clinically indicated.

The pigs were ventilated (Paco2, 4.5-5.0 kPa) throughout the experiment and were infused with $0.9 \% \mathrm{NaCl}$ (at 3 $\mathrm{mL} / \mathrm{kg} / \mathrm{hr}$ ), $50 \%$ glucose (at $0.6 \mathrm{~mL} / \mathrm{kg} / \mathrm{hr}$, except for sham-operated animals, which received only half that amount to make the glucose levels comparable between the groups), and $20 \%$ human albumin (at $0.66 \mathrm{~mL} / \mathrm{kg} / \mathrm{hr}$, to counteract intra-abdominal fluid loss during and after surgery), as described previously (21-25). Normal core body temperature was maintained at $38.5 \pm 1^{\circ} \mathrm{C}$. Heparin was used to keep the activated clotting time $>100 \mathrm{sec}(>180 \mathrm{sec}$ during MARS).

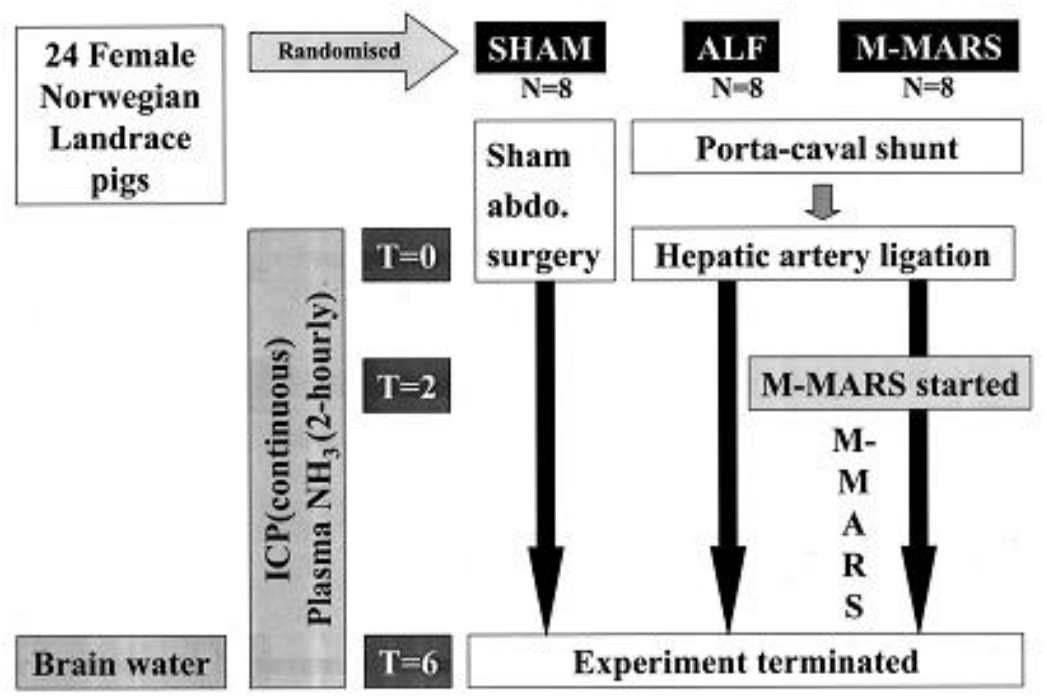

Figure 1.An outline of the study design (ALF, acute liver failure; ICP, intracranial pressure; M-MARS, modified Molecular Adsorbents Recirculating System).

\section{Catheter Placement.}

A very thin catheter developed by Ten Have et al. $(26,27)$ was introduced into the abdominal aorta. MARS was performed through an 11.5-French dual lumen catheter (Mahurkar, Tyco Healthcare, Gosport, Hampshire, UK) in the inferior vena cava (positioned during abdominal surgery). ALF and sham animals also received a vena caval catheter to be comparable. A 7-French pigtail catheter (Cordis, Miami, FL) was inserted via the left carotid artery into the left ventricle of the heart for microsphere injection. Position was confirmed by online pressure curves.

\section{Use of M-MARS.}

MARS (Monitor 1, Teraklin AG, Rostock, Germany) (15) dialyses blood across an albumin-impregnated membrane against 20\% human albumin, the premise being that albumin-bound toxins in the blood detach, bind to free binding sites on the membrane, and pass on to albumin in the dialysate. Normally, the dialysate is then cleansed by hemodialysis/filtration (removing water-soluble toxins) and activated charcoal and anion-exchanger (adsorbing albumin-bound toxins), is "regenerated," and adsorbs more toxins from the blood $(15,16,18)$. Because the present study was designed to specifically evaluate the role of albumin dialysis in ALF, hemofiltration/dialysis was not performed (i.e., there was no additional removal of free water/water-soluble toxins, other than what might be removed by a closed-circuit recirculating albumin dialysis), and the renal part of the circuit was clamped off. Thus, this was a modified MARS circuit (M-MARS). Albumin recirculation continued, as has been previously described (Fig. 2). A roller pump (Stöckert Shiley, Munich, Germany) was used to run the blood circuit at $150 \mathrm{~mL} / \mathrm{min}$, with the albumin dialysate circulated by the MARS pump also at $150 \mathrm{~mL} / \mathrm{min}$. 
Sen, S. et al., 2006. Effect of albumin dialysis on intracranial pressure increase in pigs with acute liver failure: a randomized study. Critical Care Medicine, 34(1), p.158-164.

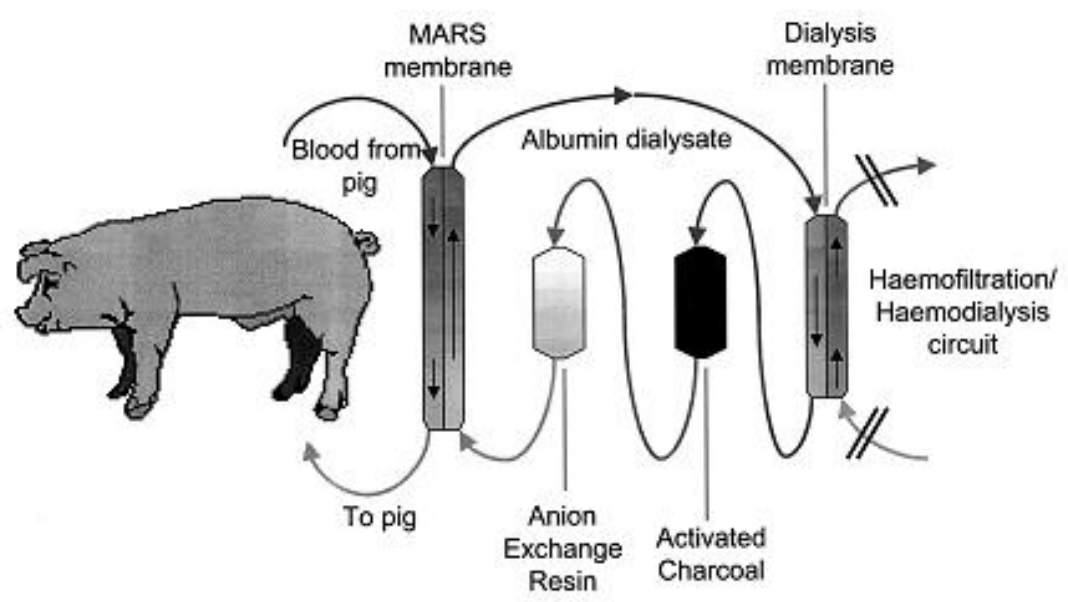

Figure 2.A schematic diagram of the modified Molecular Adsorbents Recirculating System (M-MARS) circuit. Blood is dialyzed against $20 \%$ albumin across the MARS membrane. The albumin dialysate is sequentially cleansed by the activated charcoal column and the anion exchange resin column and is thus recirculated. The segments for the renal module of the circuit have been clamped off.

\section{ICP Monitoring.}

A burr hole was created over the right frontal region of the skull $(2 \mathrm{~cm}$ lateral, $1 \mathrm{~cm}$ rostral from bregma and $1 \mathrm{~cm}$ ventral), the dura mater was incised, and a stable drift-free ICP transducer for continuous measurements (Codman MicroSensor, Johnson \& Johnson, Raynham, MA) was inserted into the frontal cortex at least $1 \mathrm{hr}$ before completion of abdominal surgery. The burr hole was sealed with bone wax to ensure stable positioning of the catheter and to prevent pressure release. ICP monitoring has been described in detail elsewhere (21-24). Average values from the last 5 mins before each time point were used for analysis of the continuous data. After the experiments were terminated, a craniotomy was performed and the brain was examined for any intracranial hemorrhage.

\section{Brain Water Measurement.}

Following termination of the experiments, the brain was rapidly removed and samples were dissected from the frontal cortex (grey matter) and adjacent subcortical white matter of the frontal lobe, as well as the cerebellar cortex. Brain tissue water content (measure of cerebral edema) was determined by the previously described gravimetric technique, with use of kerosene and bromobenzene to generate a liquid column with a known linear density gradient (28).

\section{CBF Measurement.}

The method of blood flow determination with fluorescent microspheres has been described in detail elsewhere (29). In brief, $1 \times 106$ fluorescent microspheres (polystyrene, $15.5 \mu \mathrm{m} \pm 2 \%$; Molecular Probes, Eugene, OR) were injected via the left ventricular catheter at time $=0$ and $6 \mathrm{hrs}$. Simultaneously, a reference arterial sample was collected from the arterial cannula at $4 \mathrm{~mL} / \mathrm{min} \times 2$ mins (Harvard withdrawal pump, Harvard Apparatus, Millis, MA) which allowed for the calculation of absolute blood flow. At time $=6 \mathrm{hrs}$, brain tissue samples (forebrain, cerebellum) were collected and stored at $-80^{\circ} \mathrm{C}$ until analysis. Samples were weighed before digestion in ethanolic $\mathrm{KOH}$ (Sigma, Poole, $\mathrm{UK}$ ) in a $60^{\circ} \mathrm{C}$ oven over $24 \mathrm{hrs}$, before vacuum filtration through an $8-\mu \mathrm{m}$ polycarbonate membrane (Kunstoff, Grafenhausen, Germany) (30). The filtered microspheres were washed with 1\% Triton-X 100 (Sigma) and stored in the dark until measurement. Immediately before measurement, the microspheres were dissolved in diethylene glycol monoethyl ether acetate (Sigma) and analyzed with a fluorescence spectrometer (LS50B, Perkin-Elmer, Norwalk, CT) and an autosampler and diluter station with common autosampler software (models AS90/91and DS6, respectively, FLWinLab, Perkin-Elmer). Values are expressed as $\mathrm{mL} / \mathrm{min} / 100 \mathrm{~g}$ tissue (wet weight). 
Sen, S. et al., 2006. Effect of albumin dialysis on intracranial pressure increase in pigs with acute liver failure: a randomized study. Critical Care Medicine, 34(1), p.158-164.

\section{Plasma Measurements for Ammonia and Inflammatory Mediators/Surrogate Markers.}

Arterial blood was collected every $2 \mathrm{hrs}$ and centrifuged, and the plasma was stored at $-70^{\circ} \mathrm{C}$ for subsequent analysis. Ammonia levels were determined with an ammonia reagent kit (171-B, Sigma Diagnostics, St. Louis, MO) by an automated enzymatic method (Cobas Fara II, Roche, Basel, Switzerland). Cytokines (interleukin [IL]-6, IL-8, and tumor necrosis factor [TNF]-[alpha]) were detected with commercially available porcine cytokine sets (R\&D Systems, Minneapolis, MN) used according to the manufacturer's instructions (lower limit for detection, $5 \mathrm{pg} / \mathrm{mL}$ ). Malondialdehyde was detected with a modified Thiobarbituric Acid Reactive Substances (TBARS) assay, described by Lapenna et al. (31), wherein the major interfering/oxidizable component in the plasma is inhibited by addition of sodium sulfate. F2-isoprostanes (free 8-isoprostane F2[alpha]) was assayed with a commercial enzyme immunoassay kit (Cayman Chemical, Ann Arbor, MI) according to the manufacturer's instructions; $200 \mu \mathrm{L}$ plasma was deproteinized with $600 \mu \mathrm{L}$ ethanol containing 3H-prostaglandin E2 (3H-PGE2) as an internal standard to account for losses. After centrifugation the supernatant was reduced to near-dryness, and $2 \mathrm{~mL}$ acetic acid was added and applied to a preconditioned C18 SPE cartridge (Waters, Milford, MA). The column was washed with water, dried with nitrogen, and eluted with high-performance-liquid-chromatography-grade hexane. The prostanoid fraction was eluted with $5 \mathrm{~mL}$ ethylacetate containing $1 \%$ methanol, the eluant was reduced to dryness and reconstituted in $450 \mu \mathrm{L}$ of enzyme immunoassay buffer (100 $\mu \mathrm{L}$ was used to determine recovery of 3H-PGE2), and $50 \mu \mathrm{L}$ was added to the enzyme immunoassay plate with isoprostane tracer and antibody. Isoprostane levels were determined with reference to authentic standards and were corrected for losses.

\section{Statistics.}

Results are expressed as mean \pm sem. Significance of difference within a group was tested by paired Student's t-test, and between-groups differences were tested by unpaired Student's t-test or two-way ANOVA, as appropriate; $\mathrm{p}<.05$ was considered statistically significant. GraphPad software (Prism 4.0, GraphPad Software, San Diego, CA) was used.

\section{RESULTS}

Three pigs were excluded: one sham and one ALF, because of intracranial hemorrhage, and one ALF, because of technical problems with ICP monitoring; 21 pigs (sham, 7; ALF, 6; ALF + M-MARS, 8) were ultimately included.

\section{Intracranial Pressure.}

Following liver devascularization, the ALF group ( $7.0 \pm 0.8$ to $15.5 \pm 1.7 \mathrm{~mm} \mathrm{Hg}$ ) developed a significant increase in ICP over $6 \mathrm{hrs}(121.4 \pm 22.1 \% ; \mathrm{p}=.005)$ in comparison with the sham group $(8.4 \pm 0.9$ to $9.7 \pm 1.2 \mathrm{~mm} \mathrm{Hg}$, a $15.3 \pm$ $13.1 \%$ increase $[\mathrm{p}>.05]$; ALF vs. sham, $\mathrm{p}<.05)$. This rise was attenuated in the ALF + M-MARS group $(9.1 \pm 1.0$ to $14.5 \pm 1.6 \mathrm{~mm} \mathrm{Hg}$, a $58.9 \pm 16.0 \%$ increase $[\mathrm{p}<.001]$; ALF + M-MARS vs. ALF, $\mathrm{p}<.05)$. However, the ICP in the ALF + M-MARS group remained significantly higher than in the sham group (ALF + M-MARS vs. shams, $p<.05$ ) (Fig. 3). Similarly, the absolute increase of ICP over $6 \mathrm{hrs}$ was significantly greater in the ALF group ( $8.5 \pm 1.5 \mathrm{~mm} \mathrm{Hg})$ than in the sham group ( $1.3 \pm 0.6 \mathrm{~mm} \mathrm{Hg} ; \mathrm{p}<.01)$. This rise was attenuated with M-MARS ( $5.4 \pm 1.0 \mathrm{~mm} \mathrm{Hg}$; $<.05 \mathrm{vs}$. ALF), although it was still significantly greater than in the sham group $(\mathrm{p}<.01)$. Finally, the area under the curve for relative change in ICP ( $\mathrm{mm} \mathrm{Hg}$ ) vs. time over the duration of M-MARS dialysis (time $=2-6 \mathrm{hrs}$ ) was significantly lower with M-MARS (6.5 $\pm 0.9 \mathrm{~mm} \mathrm{Hg} / \mathrm{hr})$ than in the ALF group $(11.5 \pm 2.4 \mathrm{~mm} \mathrm{Hg} / \mathrm{hr} ; \mathrm{p}<.05)$. 


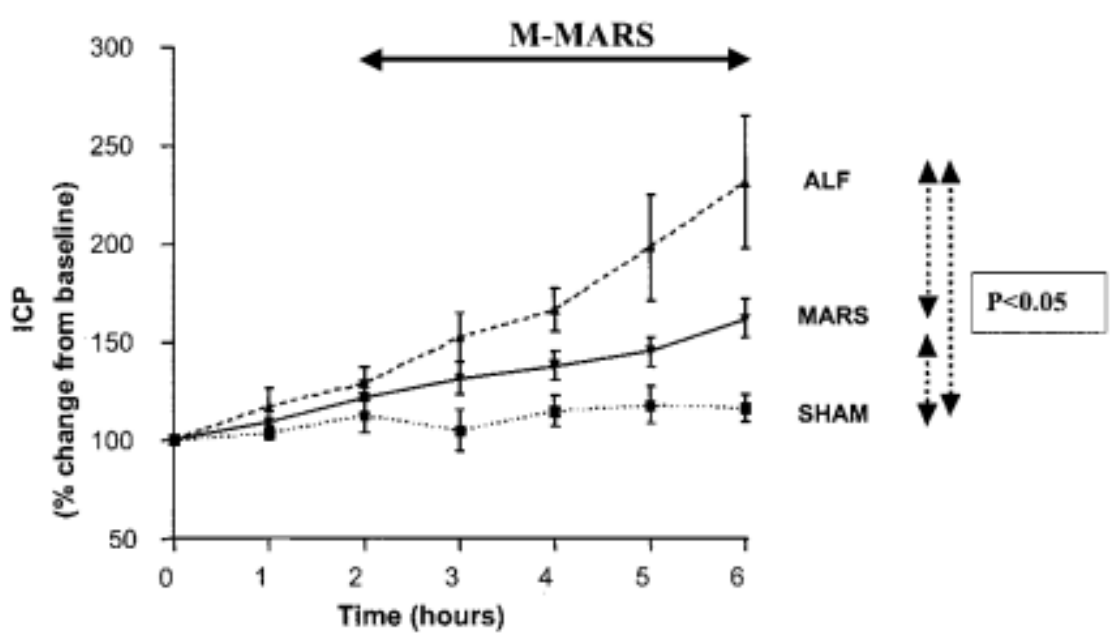

Figure 3.Rise of intracranial pressure (ICP, expressed as percentage change from baseline) in the three groups over the duration of the study (ALF, acute liver failure; M-MARS, modified Molecular Adsorbents Recirculating System).

\section{Brain Water.}

Brain tissue water content in the grey and white matter of the frontal lobe at $6 \mathrm{hrs}$ was significantly higher in the ALF group than in the sham group. M-MARS prevented an increase in ALF-induced water content in the white matter $(\mathrm{p}=$ .04 ) but not in the grey matter. Cerebellar water content did not significantly differ between the three groups (Fig.4).
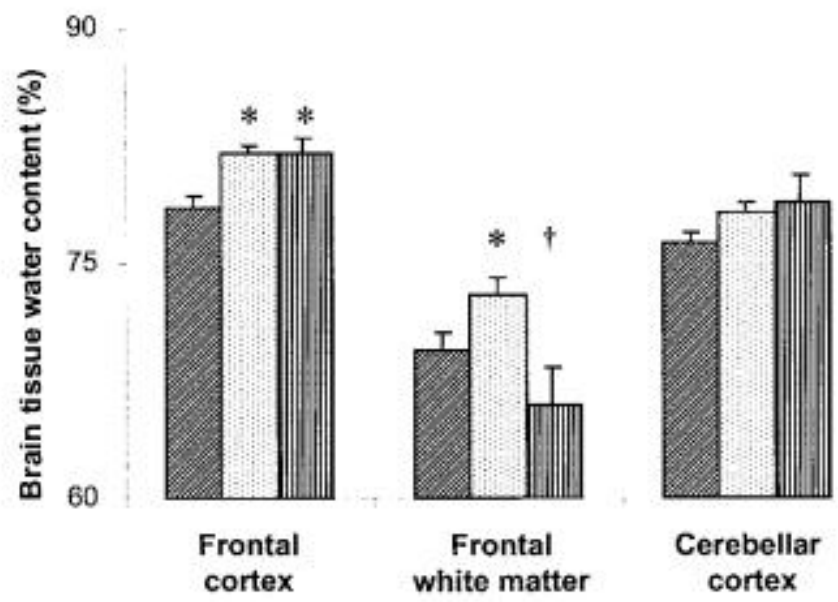

Figure 4.Brain water content per unit mass of brain tissue (g water/g tissue, expressed as a percentage) at the end of the experiments (time $=6)$ in the three groups of pigs ( ${ }^{*} \mathrm{p}<.05 \mathrm{vs.} \mathrm{sham;}+\mathrm{p}<.05 \mathrm{vs}$. ALF;ALF,acute liver failure;M-MARS,modified Molecular Adsorbents Recirculating System)

\section{Cerebral Blood Flow.}

$\mathrm{CBF}$, measured at time $=0$ and $6 \mathrm{hrs}$ in the forebrain and the cerebellum, was not significantly different over time or amongst brain regions within or between any of the three groups (Table 1). 
Sen, S. et al., 2006. Effect of albumin dialysis on intracranial pressure increase in pigs with acute liver failure: a randomized study. Critical Care Medicine, 34(1), p.158-164.

Table 1.Cerebral blood flow $(\mathrm{ml} / \mathrm{min} / 100 \mathrm{~g} ;$ mean \pm SEM) at baseline (time $=0 \mathrm{hrs}$ ) and at the end of the experiments (time $=6 \mathrm{hrs}$ ) in the three groups of pigs

\begin{tabular}{lccc}
\hline & \multicolumn{3}{c}{ Cerebral blood flow, $\mathrm{mL} / \mathrm{min} / 100 \mathrm{~g}$} \\
\cline { 2 - 4 } Brain Area: Time Point & Sham & ALF & ALF + M-MARS \\
\hline $\begin{array}{l}\text { Forebrain } \\
\quad 0 \text { hrs }\end{array}$ & $59 \pm 14$ & $38 \pm 8$ & \\
$\quad \begin{array}{l}\text { h hrs } \\
\text { Cerebellum }\end{array}$ & $31 \pm 16$ & $33 \pm 13$ & $49 \pm 7$ \\
$\quad 6$ hrs & $48 \pm 19$ & $41 \pm 11$ & $29 \pm 9$ \\
\hline
\end{tabular}

ALF, acute liver failure; M-MARS, modified Molecular Adsorbents Recirculating System.

\section{Ammonia.}

Elevation of arterial ammonia occurred over 6 hrs in the ALF group and was significantly higher than in the sham group ( $\mathrm{p}$.0001). The ALF + M-MARS group also developed hyperammonemia, which was not significantly different from that in the ALF group but significantly higher than in the sham group ( $<.0001)$ (Fig. 5).

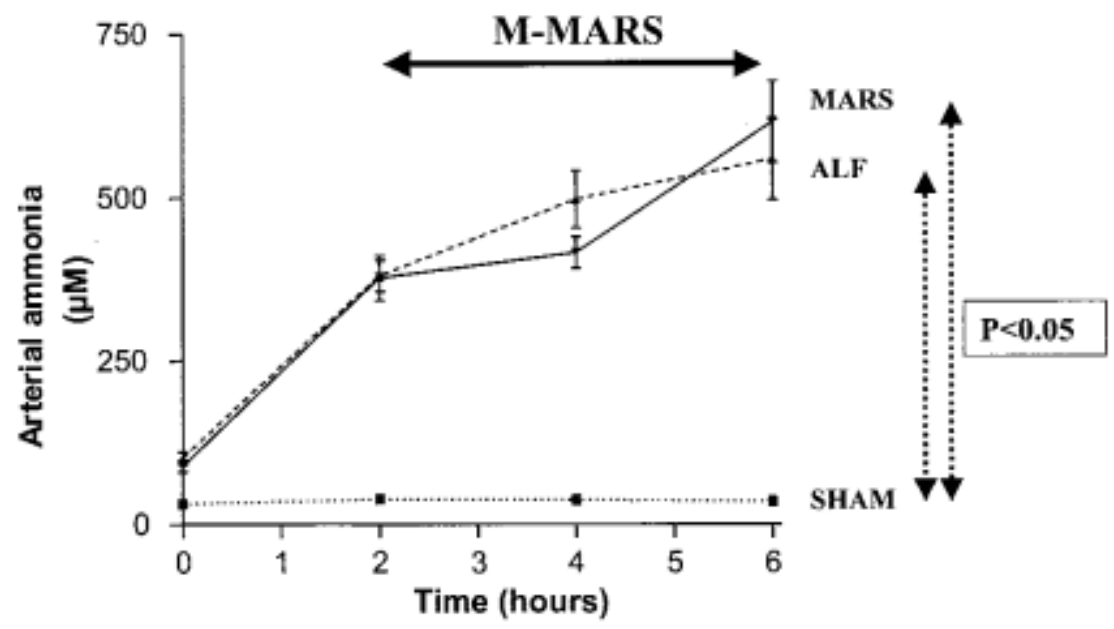

Figure 5.Rise in arterial ammonia over the duration of the study period in the three groups (ALF, acute liver failure;M-MARS, modified Molecular Adsorbents Recirculating System).

\section{Inflammatory Markers.}

None of the inflammatory mediators or surrogate markers studied (cytokines: IL-6, IL-8, TNF-[alpha]) changed significantly over time in any of the groups. Plasma malondialdehyde, an oxidative stress marker, increased significantly after $6 \mathrm{hrs}$ in the ALF and ALF + M-MARS groups but not in the sham group. The change relative to baseline (time $=0$ ) in the ALF group (120.1 $\pm 42.0 \%$ increase) was significantly higher than in the sham group (22.1 $\pm 9.3 \%$ decrease; $p<.01$ ), whereas that in the ALF + M-MARS group (35.2 $\pm 8.4 \%$ increase) was significantly lower than in the ALF group $(\mathrm{p}<.05)$. The percentage changes were not significantly different between the sham and ALF + M-MARS groups, although 6-hr levels were significantly higher in the latter. Plasma F2-isoprostane, another oxidative stress marker, did not increase significantly in any of the groups. The increases relative to baseline in the ALF $(22.1 \pm 16.4 \%)$ and ALF + M-MARS groups $(21.7 \pm 15.0 \%)$ were significantly higher than in the sham group $(20.0 \pm 7.2 \%$ decrease; $\mathrm{p}<.05)$ but not significantly different amongst themselves (Table 2$)$. 
Sen, S. et al., 2006. Effect of albumin dialysis on intracranial pressure increase in pigs with acute liver failure: a randomized study. Critical Care Medicine, 34(1), p.158-164.

Table 2.Plasma levels of cytokines, malondialdehyde, and F2-isoprostanes in the three groups of pigs at baseline (time $=0 \mathrm{hrs}$ ) and at the end of the experiments (time=6)

\begin{tabular}{|c|c|c|c|c|c|c|}
\hline \multirow[b]{3}{*}{ Variable } & \multicolumn{6}{|c|}{ Plasma level, mean \pm SEM } \\
\hline & \multicolumn{2}{|c|}{ Sham } & \multicolumn{2}{|c|}{ ALF } & \multicolumn{2}{|c|}{ ALF + M-MARS } \\
\hline & $0 \mathrm{hrs}$ & $6 \mathrm{hrs}$ & 0 hrs & $6 \mathrm{hrs}$ & $0 \mathrm{hrs}$ & $6 \mathrm{hrs}$ \\
\hline IL-6, $\mu \mathrm{M}$ & BDL & BDL & BDL & BDL & BDL & BDL \\
\hline IL-8, $\mu \mathrm{M}$ & BDL & BDL & BDL & BDL & BDL & BDL \\
\hline $\mathrm{TNF}-\alpha, \mu \mathrm{M}$ & BDL & BDL & BDL & BDL & BDL & BDL \\
\hline Malondialdehyde, $\mu \mathrm{M}$ & $1.4 \pm 0.2$ & $1.1 \pm 0.2$ & $1.6 \pm 0.4$ & $2.9 \pm 0.3^{b, c}$ & $1.8 \pm 0.2$ & $2.4 \pm 0.1^{b, c}$ \\
\hline F2-isoprostanes, $\mathrm{pg} / \mathrm{mL}$ & $100.1 \pm 17.0$ & $76.0 \pm 13.0^{\alpha}$ & $89.6 \pm 8.7$ & $105.5 \pm 15.4$ & $83.9 \pm 10.0$ & $96.6 \pm 10.8$ \\
\hline
\end{tabular}

\section{DISCUSSION}

ALF causes cerebral edema, leading to increased ICP and consequent morbidity and mortality (1-4). However, its underlying mechanisms have not been fully elucidated. Previous studies have consistently shown an improvement in the mental state of patients whose liver failure is treated with MARS $(12-14,20)$. The present study investigated the pathophysiological factors responsible for increased ICP in ALF, with use of M-MARS dialysis as an experimental tool. A porcine liver-devascularized ALF model previously demonstrated to have a characteristic increase in ICP (21-24) and large enough to evaluate an extracorporeal device was used. The rise of ICP and increase in brain water without significant change in CBF and inflammatory markers suggest a significant initiating role of ammonia in the pathogenesis of increased ICP in ALF. The attenuation of ICP increase with M-MARS was not due to reduced arterial ammonia and was independent of changes in CBF, peripheral inflammatory markers, or systemic hemodynamics (which remained unaltered with M-MARS; data reported elsewhere (32)), suggesting that other undefined mechanisms are important. Our data also demonstrate asymmetric distribution of brain water, possibly implicating different types of astrocytes or other cell types in the pathogenesis of brain edema in ALF. Normalization of brain water in the white matter by M-MARS suggests this region is a possible new therapeutic target.

A noteworthy point is the variation in baseline ICP between the three groups, with the difference between ALF (lowest) and ALF + M-MARS groups (highest) tending toward statistical significance ( $p=.09$ ), although all baseline values were still within normal limits. The probable reason is interlitter variation, with uneven distribution of animals from the three litters used for the study between the three groups, in spite of the randomization protocol used. This confounded analysis of the ICP data with use of actual values of the groups. We therefore analyzed the data with use of percentage changes, differences in absolute changes ([DELTA] ICP), and area under the curve for relative change in ICP vs. time. All three of the statistical methods used to overcome the difficulties introduced by variations in the baseline indicate a significant rise of ICP in ALF in comparison with sham, as well as a significant attenuation with albumin dialysis. Moreover, whereas analysis of absolute ICP values is important to interpret the clinical relevance of data, the present study was designed to allow early institution of albumin dialysis to attenuate an increase in ICP. Thus, the absolute ICP values cannot be directly translated to the clinical setting of ALF, but the change in ICP can be used to study underlying pathophysiology.

Hyperammonemia is thought to be central in the pathogenesis of increased ICP in ALF (6), and this is supported in our model where intracranial hypertension was accompanied by rising arterial ammonia in ALF (as opposed to sham). Similar arterial levels have previously been shown to be associated with high brain ammonia extraction (33) and brain stem herniation in ALF patients (6). However, even though M-MARS attenuated the rise of ICP, hyperammonemia persisted, suggesting other factors are important in the development of intracranial hypertension. Removal of these putative factors can potentially result in a beneficial lowering of ICP. Unfortunately, the presence of 
Sen, S. et al., 2006. Effect of albumin dialysis on intracranial pressure increase in pigs with acute liver failure: a randomized study. Critical Care Medicine, 34(1), p.158-164.

extensive intracranial arteriovenous anastomoses $(34,35)$ in pigs meant that further analyses for brain ammonia flux/extraction (with use of arterial and reverse jugular venous samples) would be difficult to interpret.

Cytotoxic brain edema is commonly observed in ALF and is thought to be the underlying mechanism of intracranial hypertension. Most studies investigating this phenomenon concentrate on brain water changes in the frontal cortex (grey matter) in different animal models $(7,8,36)$. This study explored the possibility of regional cerebral differences by measuring brain water in the frontal cortex (grey matter), adjacent subcortical white matter, and cerebellar cortex. In addition to the consistently observed increase in brain water in the grey matter in the ALF group, a significant increase was also noted in white matter but not in the cerebellum, a finding emphasizing that cerebral edema in ALF is not entirely confined to grey matter. This may provide novel insights into pathogenesis. It is known that astrocyte swelling (possibly due to accumulation of the ammonia-detoxification product glutamine) in grey matter causes brain edema in $\operatorname{ALF}(4,37)$. However, astrocytes are also found in white matter, although of a different type (fibrous astrocytes, compared to protoplasmic astrocytes in grey matter). This suggests that astrocytes in general are prone to swell and/or that other cells in white matter (e.g., oligodendrocytes) contribute to brain edema in ALF. The additional observation of normalization of white matter water content with albumin dialysis, without improvement of grey matter edema, implies that white matter water content may be the more labile component and more amenable to therapeutic interventions. Anecdotal reports on rat models of ALF demonstrating regional differences of brain water between forebrain (predominantly grey matter) and hindbrain (predominantly white matter) (38-40) support our findings.

Reports of CBF in the setting of ALF have varied widely (41-44), perhaps because of the differences in techniques used and the lack of longitudinal observations, which would define a clearer temporal resolution. The technique using microspheres has previously been used in pig models and has been shown to compare well with other methods of measurement (45-48). In our model, no significant change in CBF in the forebrain or the cerebellum (hindbrain) accompanied either the rise in ICP with ALF or the decrease with albumin dialysis. All values observed remained within normal limits for pigs. This observation, suggesting that an increase in CBF does not initiate the rise in ICP observed in the ALF pig, is at variance with data from experimental studies involving porta-caval-shunted ammonia-infused rats (36). This may reflect differences in the models and timing of measurements. Our results are supported by observations in patients with ALF, from which we recently showed that increased CBF was associated with bursts of ICP, to values $>20 \mathrm{~mm} \mathrm{Hg}$, but an increase in CBF was not found to be the important initiating event in the pathogenesis of intracranial hypertension (49). It is interesting that an ICP $>20 \mathrm{~mm} \mathrm{Hg}$ was observed in only two pigs (both $21 \mathrm{~mm} \mathrm{Hg}$ ) in our study.

We also investigated the role of mediators of inflammation (or surrogate markers) in relation to these cerebral effects. Takada et al. (50) showed in a pig model of ALF that animals administered lipopolysaccharide and amatoxin intraportally developed greater intracranial hypertension than animals given amatoxin alone. ALF patients who had higher systemic inflammatory response syndrome scores or who were overtly infected were more likely to develop intracranial hypertension $(51,52)$. Malondialdehyde levels showed statistically significant changes but remained within the normal range and were unlikely to be of pathophysiological relevance. F2-isoprostanes did not increase significantly in ALF, but the change from baseline was significantly higher than in the sham group, mainly because of a significant reduction in levels in the latter group (perhaps due to recovery from surgical stress). None of the proinflammatory cytokines studied increased significantly in any of the groups, suggesting that the cerebral changes over 6 hrs in our model developed independently of any inflammation, including oxidative stress. Hence, it was not possible to evaluate the role of MARS in removing cytokines, as has been reported recently (53). Our results support the notion that inflammation is unlikely to be an important initiating factor in the pathogenesis of intracranial hypertension in ALF, but as we have recently observed in ALF patients, it may be more important in the later stages of ALF (49).

The cerebral effects of albumin dialysis observed in the present study were evident with a 4-hr session started $2 \mathrm{hrs}$ after the induction of ALF, implying that early institution of therapy for ALF patients might bring about a rapid

The final publication is available at http://dx.doi.org/10.1097/01.CCM.0000196203.39832.3C 
Sen, S. et al., 2006. Effect of albumin dialysis on intracranial pressure increase in pigs with acute liver failure: a randomized study. Critical Care Medicine, 34(1), p.158-164.

clinical response. Hemodialysis may worsen intracranial hypertension in ALF (54-56); therefore, closed albumin dialysis without additional hemodialysis/filtration may be a worthwhile option. There was no significant change in arterial ammonia levels, even though ammonia was detectable in the MARS dialysate (data not shown). Although it is possible that absence of the renal circuit in M-MARS could have reduced ammonia removal, the results of the present study are in keeping with our previous observation with conventional MARS (with continuous venovenous hemofiltration) in patients with acute or chronic liver failure, of marked improvement of hepatic encephalopathy despite unchanged arterial ammonia (even though ammonia was being removed by the circuit) (57).

In the present study, a modified MARS circuit was used without any renal replacement module to evaluate albumin dialysis without additional removal of water-soluble toxins. Although this was advantageous in studying the underlying pathophysiological changes, our results cannot be directly extrapolated to systems using albumin dialysis with hemofiltration/dialysis. On a similar note, porcine blood was dialyzed against human albumin. Human and porcine albumin have similar molecular weights (66-67 kDa) (58), and although their binding properties do vary (59), their affinity for substances such as bilirubin are very similar (60). Thus, although the exact rate of change may be affected by this interspecies difference, we believe our results to be essentially valid for albumin dialysis in human patients. On a similar note, although human albumin was intravenously infused into the pigs, no reaction was observed against the xenogenic protein, which is in keeping with all the previous observations in studies using this model (21-24).

The results of this study show that M-MARS has beneficial effects on ICP in a devascularized pig model of ALF. Regional differences exist for brain edema, with white matter edema being more amenable to therapeutic interventions such as albumin dialysis. Unidentified factors in addition to hyperammonemia appear to be important in the pathogenesis of increased ICP in ALF, which are altered by albumin dialysis. Identifying these putative factors and understanding their intracerebral effects may provide novel therapeutic targets.

\section{ACKNOWLEDGEMENTS}

Supported by the Liver Research Foundation (London, UK), Norwegian Research Council (Oslo, Norway), and Sir Siegmund Warburg Voluntary Settlement (London, UK). Teraklin AG (Rostock, Germany) provided MARS kits. Dr. Rose was supported by a grant from the Alexander von Humboldt Foundation.

None of the authors have any financial interests to disclose.

\section{REFERENCES}

1. Makin AJ, Wendon J, Williams R: A 7-year experience of severe acetaminophen-induced hepatotoxicity (1987-1993).

Gastroenterology 1995; 109:1907-1916

2. O'Grady JG, Alexander GJ, Hayllar KM, et al: Early indicators of prognosis in fulminant hepatic failure. Gastroenterology 1989; $97: 439-445$

3. Ascher NL, Lake JR, Emond JC, et al: Liver transplantation for fulminant hepatic failure. Arch Surg 1993; 128:677-682

4. Butterworth RF: Pathophysiology of hepatic encephalopathy: A new look at ammonia. Metab Brain Dis 2002; 17:221-227

5. Jalan R: Intracranial hypertension in acute liver failure: Pathophysiological basis of rational management. Semin Liver Dis 2003; 23:271-282

6. Clemmesen JO, Larsen FS, Kondrup J, et al: Cerebral herniation in patients with acute liver failure is correlated with arterial ammonia concentration. Hepatology 1999; 29:648-653

The final publication is available at http://dx.doi.org/10.1097/01.CCM.0000196203.39832.3C 
Sen, S. et al., 2006. Effect of albumin dialysis on intracranial pressure increase in pigs with acute liver failure: a randomized study. Critical Care Medicine, 34(1), p.158-164.

7. Rose C, Michalak A, Rao KV, et al: L-ornithine-L-aspartate lowers plasma and cerebrospinal fluid ammonia and prevents brain edema in rats with acute liver failure. Hepatology 1999; 30:636-640

8. Rose C, Michalak A, Pannunzio M, et al: Mild hypothermia delays the onset of coma and prevents brain edema and extracellular brain glutamate accumulation in rats with acute liver failure. Hepatology 2000; 31:872-877

9. Larsen FS: Cerebral blood flow in hyperammonemia: Heterogeneity and starling forces in capillaries. Metab Brain Dis 2002; 17:229-235

10. Jalan R, Williams R: The inflammatory basis of intracranial hypertension in acute liver failure. J Hepatol 2001; 34:940-942

11. Shawcross DL, Davies NA, Williams R, et al: Systemic inflammatory response exacerbates the neuropsychological effects of induced hyperammonemia in cirrhosis. J Hepatol 2004; 40:247-254

12. Mitzner SR, Klammt S, Peszynski P, et al: Improvement of multiple organ functions in hepatorenal syndrome during albumin dialysis with the molecular adsorbent recirculating system. Ther Apher 2001; 5:417-422

13. Sorkine P, Ben Abraham R, Szold 0, et al: Role of the molecular adsorbent recycling system (MARS) in the treatment of patients with acute exacerbation of chronic liver failure. Crit Care Med 2001; 29:1332-1336

14. Stange J, Mitzner SR, Risler T, et al: Molecular adsorbent recycling system (MARS): Clinical results of a new membrane-based blood purification system for bioartificial liver support. Artif Organs 1999; 23:319-330

15. Stange J, Mitzner S, Ramlow W, et al: A new procedure for the removal of protein bound drugs and toxins. Asaio J 1993; 39:M621-M625

16. Stange J, Mitzner S: A carrier-mediated transport of toxins in a hybrid membrane: Safety barrier between a patients blood and a bioartificial liver. Int J Artif Organs 1996; 19:677-691

17. Sen S, Mookerjee RP, Davies NA, et al: Review article: the Molecular Adsorbents Recirculating System (MARS) in liver failure. Aliment Pharmacol Ther 2002; 16(Suppl 5):32-38

18. Stange J, Ramlow W, Mitzner S, et al: Dialysis against a recycled albumin solution enables the removal of albumin-bound toxins. Artif Organs 1993; 17:809-813

19. Stange J, Hassanein TI, Mehta R, et al: The molecular adsorbents recycling system as a liver support system based on albumin dialysis: A summary of preclinical investigations, prospective, randomized, controlled clinical trial, and clinical experience from 19 centers. Artif Organs 2002; 26:103-110

20. Schmidt LE, Svendsen LB, Sorensen VR, et al: Cerebral blood flow velocity increases during a single treatment with the molecular adsorbents recirculating system in patients with acute on chronic liver failure. Liver Transpl 2001; 7:709-712

21. Ytrebo LM, Nedredal GI, Langbakk B, et al: An experimental large animal model for the assessment of bioartificial liver support systems in fulminant hepatic failure. Scand J Gastroenterol 2002; 37:1077-1088

22. Ytrebo LM, Ingebrigtsen T, Nedredal GI, et al: Protein S-100beta: A biochemical marker for increased intracranial pressure in pigs with acute hepatic failure. Scand J Gastroenterol 2000; 35:546-551

23. Ytrebo LM, Korvald C, Nedredal GI, et al: N-acetylcysteine increases cerebral perfusion pressure in pigs with fulminant hepatic failure. Crit Care Med 2001; 29:1989-1995

24. Ytrebo LM, Nedredal GI, Korvald C, et al: Renal elimination of protein S-100beta in pigs with acute encephalopathy. Scand J Clin Lab Invest 2001; 61:217-225

25. Sen S, Ytrebo LM, Rose C, et al: Albumin dialysis: A new therapeutic strategy for intoxication from protein-bound drugs. Intensive Care Med 2004; 30:496-501

The final publication is available at http://dx.doi.org/10.1097/01.CCM.0000196203.39832.3C 
Sen, S. et al., 2006. Effect of albumin dialysis on intracranial pressure increase in pigs with acute liver failure: a randomized study. Critical Care Medicine, 34(1), p.158-164.

26. Hallemeesch MM, Ten Have GA, Deutz NE: Metabolic flux measurements across portal drained viscera, liver, kidney and hindquarter in mice. Lab Anim 2001; 35:101-110

27. Ten Have GA, Bost MC, Suyk-Wierts JC, et al: Simultaneous measurement of metabolic flux in portally-drained viscera, liver, spleen, kidney and hindquarter in the conscious pig. Lab Anim 1996; 30:347-358

28. Marmarou A, Poll W, Shulman K, et al: A simple gravimetric technique for measurement of cerebral edema. J Neurosurg 1978; 49:530-537

29. Van Oosterhout MF, Willigers HM, Reneman RS, et al: Fluorescent microspheres to measure organ perfusion: Validation of a simplified sample processing technique. Am J Physiol 1995; 269(2 Pt 2):H725-H733

30. Raab S, Thein E, Harris AG, et al: A new sample-processing unit for the fluorescent microsphere method. Am J Physiol 1999; 276(5 Pt 2):H1801-H1806

31. Lapenna D, Ciofani G, Pierdomenico SD, et al: Reaction conditions affecting the relationship between thiobarbituric acid reactivity and lipid peroxides in human plasma. Free Radic Biol Med 2001; 31:331-335

32. Ytrebo LM, Sen S, Rose C, et al: MARS treatment improves renal function independent of systemic haemodynamics in acute liver failure: A randomized controlled study in a pig model. Hepatology 2003; 38(Suppl 1):676A.

33. Jalan R, Damink SW, Deutz NE, et al: Moderate hypothermia for uncontrolled intracranial hypertension in acute liver failure. Lancet 1999; 354:1164-1168

34. Nickel R, Schummer A, Seiferle E: The Anatomy of the Domestic Animals. Berlin, Verlag Paul Parey, 1981

35. Larsen FS: Cerebral circulation in liver failure: Ohm's law in force. Semin Liver Dis 1996; 16:281-292

36. Larsen FS, Gottstein J, Blei AT: Cerebral hyperemia and nitric oxide synthase in rats with ammonia-induced brain edema. J Hepatol 2001; 34:548-554

37. Kato M, Hughes RD, Keays RT, et al: Electron microscopic study of brain capillaries in cerebral edema from fulminant hepatic failure. Hepatology 1992; 15:1060-1066

38. Ede RJ, Gove CD, Hughes RD, et al: Reduced brain Na+, K+-ATPase activity in rats with galactosamine-induced hepatic failure: Relationship to encephalopathy and cerebral oedema. Clin Sci (Lond) 1987; 72:365-371

39. Groflin UB, Tholen H: Cerebral edema in the rat with galactosamine induced severe hepatitis. Experientia 1978; 34:1501-1503

40. Gove CD, Hughes RD, Ede RJ, et al: Regional cerebral edema and chloride space in galactosamine-induced liver failure in rats. Hepatology 1997; 25:295-301

41. Aggarwal S, Kramer D, Yonas H, et al: Cerebral hemodynamic and metabolic changes in fulminant hepatic failure: A retrospective study. Hepatology 1994; 19:80-87

42. Almdal T, Schroeder T, Ranek L: Cerebral blood flow and liver function in patients with encephalopathy due to acute and chronic liver diseases. Scand J Gastroenterol 1989; 24:299-303

43. Ede RJ, Williams RW: Hepatic encephalopathy and cerebral edema. Semin Liver Dis 1986; 6:107-118

44. Wendon JA, Harrison PM, Keays R, et al: Cerebral blood flow and metabolism in fulminant liver failure. Hepatology 1994; 19:1407-1413

45. Goddard-Finegold J, Louis PT, Rodriguez DL, et al: Correlation of near infrared spectroscopy cerebral blood flow estimations and microsphere quantitations in newborn piglets. Biol Neonate 1998; 74:376-384

The final publication is available at http://dx.doi.org/10.1097/01.CCM.0000196203.39832.3C 
Sen, S. et al., 2006. Effect of albumin dialysis on intracranial pressure increase in pigs with acute liver failure: a randomized study. Critical Care Medicine, 34(1), p.158-164.

46. Meadow W, Rudinsky B, Raju T, et al: Correlation of flow probe determinations of common carotid artery blood flow and internal carotid artery blood flow with microsphere determinations of cerebral blood flow in piglets. Pediatr Res 1999; 45:324330

47. Strauch JT, Spielvogel D, Haldenwang PL, et al: Impact of hypothermic selective cerebral perfusion compared with hypothermic cardiopulmonary bypass on cerebral hemodynamics and metabolism. Eur J Cardiothorac Surg 2003; 24:807-816

48. Madsen FF, Jensen FT, Vaeth M, et al: Regional cerebral blood flow in pigs estimated by microspheres. Acta Neurochir (Wien) $1990 ; 103(3-4): 139-147$

49. Jalan R, Olde Damink SW, Hayes PC, et al: Pathogenesis of intracranial hypertension in acute liver failure: Inflammation, ammonia and cerebral blood flow. J Hepatol 2004; 41:613-620

50. Takada Y, Ishiguro S, Fukunaga K, et al: Increased intracranial pressure in a porcine model of fulminant hepatic failure using amatoxin and endotoxin. J Hepatol 2001; 34:825-831

51. Vaquero J, Polson J, Chung C, et al: Infection and the progression of hepatic encephalopathy in acute liver failure. Gastroenterology 2003; 125:755-764

52. Rolando N, Wade J, Davalos M, et al: The systemic inflammatory response syndrome in acute liver failure. Hepatology 2000;32(4 Pt 1):734-739

53. Doria C, Mandal AL, Scott VL, et al: Noncardiogenic pulmonary edema induced by a molecular adsorbent recirculating system: Case report. J Artif Organs 2003; 6:282-285

54. Davenport A, Will EJ, Davison AM: Effect of renal replacement therapy on patients with combined acute renal and fulminant hepatic failure. Kidney Int Suppl 1993; 41:S245-S251

55. Davenport A: The management of renal failure in patients at risk of cerebral edema/hypoxia. New Horiz 1995; 3:717-724

56. Davenport A, Kirby SA: Intensive care management of patients with acute hepatic and renal failure. Contrib Nephrol 1995; $116: 22-27$

57. Sen S, Davies NA, Mookerjee RP, et al: Pathophysiological effects of albumin dialysis in acute-on-chronic liver failure: A randomized controlled study. Liver Transpl 2004; 10:1109-1119

58. Loo JA, Edmonds CG, Smith RD: Tandem mass spectrometry of very large molecules: Serum albumin sequence information from multiply charged ions formed by electrospray ionization. Anal Chem 1991; 63:2488-2499

59. Robertson A, Karp W, Brodersen R: Comparison of the binding characteristics of serum albumins from various animal species. Dev Pharmacol Ther 1990; 15:106-111

60. Athar H, Ahmad N, Tayyab S, et al: Use of fluorescence enhancement technique to study bilirubin-albumin interaction. Int J Biol Macromol 1999; 25:353-358 